\title{
Research amongst Physical Therapists in the State of Kuwait: Participation, Perception, Attitude and Barriers
}

\author{
Sameera H. Aljadi ${ }^{a}$ Hesham N. Alrowayeh ${ }^{a}$ Naser M. Alotaibi ${ }^{b}$ \\ Maqdad M. Taaqi ${ }^{a}$ Habib Alqurainic Talal A. Alshattia \\ Departments of a Physical Therapy, ${ }^{b}$ Occupational Therapy and ${ }^{c}$ Health Information Administration, Faculty of Allied \\ Health Sciences, Kuwait University, Sulaibikhat, Kuwait
}

\section{Key Words}

Physical therapy · Participation · Perceptions · Attitudes ·

Barriers · Research

\begin{abstract}
Objectives: The objectives of this descriptive study were to investigate the attitudes and perceptions of physical therapists regarding research, the intention to engage in research and the barriers to participating in research amongst physical therapists in the State of Kuwait. Subjects and Methods: A previously validated questionnaire was distributed to 200 non-randomly selected physical therapists. The questionnaire gathered demographic data as well as information regarding research-related activities. Descriptive statistics, frequency and $x^{2}$ analyses were used in this study. Results: Of the 200 questionnaires distributed to physical therapists 122 (61\%) were completed and returned. The physical therapists had a positive attitude towards reading these findings in order to update their knowledge. However, only $16(17 \%)$ of the physical therapists participated in clinical research. The common reasons given were: minimal role and reduced ability, intention and level of engagement in initiating research, probably due to work overload, time constraints and limited access to resources. Conclusions: Physical therapists in $\mathrm{Ku}$ -
\end{abstract}

\begin{tabular}{ll}
\hline KARGER & $\begin{array}{l}\text { ( } 2013 \text { S. Karger AG, Basel } \\
\text { 1011-7571/13/0226-0561\$38.00/0 Opencer }\end{array}$ \\
E-Mail karger@karger.com & $\begin{array}{l}\text { This is an Open Access article licensed under the terms of the } \\
\text { www.karger.com/mpp }\end{array}$ \\
& $\begin{array}{l}\text { Creative Commons Attribution-NonCommercial 3.0 Un- } \\
\text { ported license (CC BY-NC) (www.karger.com/OA-license), } \\
\text { applicable to the online version of the article only. Distribu- } \\
\text { tion permitted for non-commercial purposes only. }\end{array}$
\end{tabular}

wait had a positive attitude towards the application of research findings to their practice. However, they were not confident in initiating research due to work overload and lack of time as well as limited access to library resources. Therefore, we recommend stimulation to engage in research activities to be a requirement and to develop a system to improve the skills and knowledge of doing research.

() 2013 S. Karger AG, Basel

\section{Introduction}

Research is necessary to advance the practice of physical therapy in order to assist physical therapists in the development and testing of knowledge unique to their practice [1], to help in the growth of their practice and to enhance the level of patient care. Thus, the strength of physical therapy depends on research to expand its scientific basis for practice and patient care, leading to research-based practice or clinically oriented practice, a vision advocated by the American Physical Therapy Association (APTA) [2].

Worldwide, several studies investigated the importance of research perception and attitudes towards research, participation levels, intentions and the barriers

Assist. Prof. Sameera H. Aljadi, PhD, P'

Department of Physical Therapy

Faculty of Allied Health Sciences, Kuwait University

PO Box 31470, Sulaibikhat 90805 (Kuwait)

E-Mail aljadis@ @sc.edu.kw 
involved in research among physical therapists [3-10]. In general, these studies showed that physical therapists consider research as being of vital importance to the profession $[3,6,7]$. Results showed that physical therapists have a positive attitude towards research $[3,8]$ and believe it would improve the image of the profession [8].

The most commonly reported barriers to physical therapy research, however, were lack of time and funding, a high work load, and unfamiliarity with research procedures and statistics $[3,6,9,10]$. These findings were equally recognized by other health care professions [1116]. A literature search using MEDLINE, Scopus and CINAHL (Cumulative Index to Nursing and Allied Health Literature) with the key words 'physical therapy' or 'physiotherapy', 'physical therapists' or 'physiotherapists', and 'Kuwait' revealed that no prior studies had been conducted in Kuwait that investigated attitudes and perceptions of physical therapists regarding research.

Hence, the objectives of this study were to investigate: the attitudes and perceptions regarding research; levels of engagement in research, and the key barriers involved in participating in research amongst physical therapists in the State of Kuwait.

\section{Subjects and Methods}

\section{Subjects}

Six hundred physical therapists practicing in the government, private hospitals and universities in Kuwait were eligible to participate in this study. A convenient sample of 200 selected physical therapists, working in various governmental and private clinics, received an invitation to participate in the study.

\section{Methods}

A modified cross-sectional survey research design, as described below, was used to conduct this study. The study started in June 2010 and was completed in December 2010. The questionnaire, as well as the invitation letter and consent form were distributed and collected over a period of 1 week by physical therapists who were trained on the administration of the questionnaire. The letter explained the purpose of the study and assured the participant confidentiality of their responses. The study was approved by the institutional review boards at both Kuwait University and the Ministry of Health. The time taken to complete the questionnaire varied between 5 and $10 \mathrm{~min}$.

The questionnaire used in the present study developed by Eckerling et al. [12] was slightly modified by adding a demographic section to the original questionnaire. The reliability of the questionnaire had previously been reported as being high $[3,12]$. The questionnaire is composed of four sections and was modified by the authors. Section one collected demographic information including the participants' age, gender, nationality, marital status and number of children, education degree, years of experience, area of specialty, work environment, patient load and contribution to research. Section two measured four research-related dimensions: role of the participant in encouraging students and other colleagues to engage in research; ability; intent, and engagement. Each dimension included four statements addressing varied research-related activities (reading research articles to update knowledge, encouraging others to read, applying research findings to practice and initiating research projects). The participants rated the four research-related activities using a Likert scale, with responses varying from 'strongly agree' over 'agree', 'neutral' and 'disagree' to 'strongly disagree'. In section three, the participants graded the four research-related activities using a numerical grid rated from 1 to $7(-3$ to +3$)$ relating to the four research-related dimensions. A fifth research-related dimension measured was overall attitudes. Attitudes to research-related activities were rated using a semantic differential scale with four bipolar adjectives on a 7-point scale for each of the four research-related activities.

In section four, participants were asked to give their own opinion using a 5-point Likert scale regarding varied statements on work-related factors. These included information regarding time available for reading research articles and time available for planning and conducting research during working hours. The participants were also asked whether research activities were encouraged by their superiors, colleagues and the management. Statements regarding the ease of access to the electronic resources and research articles at the participants' workplace were also assessed. Finally, two open-ended questions were added by the authors of the current study to the original questionnaire. The participants were asked to list the scientific journals that contain relevant physical therapy research and the journals the participants read on a regular basis.

\section{Data Analyses}

Descriptive statistics including number and percentage for the demographical data (gender, age, etc.) of all participants were calculated. Medians, upper and lower quartiles, means and standard deviations for the five research-related dimensions (1) role, (2) ability, (3) intent, (4) engagement and (5) attitude index by the four research activities (1) reading research, (2) encourage colleagues to read, (3) apply research findings and (4) initiate research were also calculated. Similarly, medians, upper and lower quartiles, number and frequency of work-related factor ratings were calculated. Frequencies and cross-tabulations were used to assess the association between demographics and research-related dimensions using $\chi^{2}$ tests. Statistical significance was evaluated at $\alpha=0.05$; statistical analyses were conducted using SPSS, version 16 (SPSS, Chicago, Ill., USA).

\section{Results}

Of the 200 physical therapists to whom the questionnaires were given, 122 (61\%) completed and returned the questionnaires; no questionnaire was returned with less than $95 \%$ of the total questions answered. Of the 122 who completed and returned the questionnaire, 55 were men (mean age: $36.0 \pm 9$ years; range: $24-63$ years) and 67 women (mean age: $33.0 \pm 8$ years; range: $21-55$ years). The overall mean age of the study participants was $34.3 \pm$ 
Table 1. Medians, upper and lower quartiles, means \pm SD for role, ability, intent and engagement by research activity

\begin{tabular}{|c|c|c|c|c|c|c|c|c|}
\hline & \multicolumn{2}{|l|}{ Role } & \multicolumn{2}{|l|}{ Ability } & \multicolumn{2}{|l|}{ Intent } & \multicolumn{2}{|l|}{ Engagement } \\
\hline & median $\left(\mathrm{q}_{1}, \mathrm{q}_{3}\right)$ & mean $\pm S D$ & median $\left(\mathrm{q}_{1}, \mathrm{q}_{3}\right)$ & mean \pm SD & median $\left(\mathrm{q}_{1}, \mathrm{q}_{3}\right)$ & mean $\pm \mathrm{SD}$ & median $\left(\mathrm{q}_{1}, \mathrm{q}_{3}\right)$ & mean $\pm \mathrm{SD}$ \\
\hline $\begin{array}{l}\text { Reading research to } \\
\text { update knowledge }\end{array}$ & $5.0(4.0,5.0)$ & $4.55 \pm 0.74$ & $5.0(4.0,5.0)$ & $4.6 \pm 0.55$ & $5.0(4.0,5.0)$ & $4.41 \pm 0.77$ & $4.0(4.0,5.0)$ & $4.06 \pm 0.96$ \\
\hline Encouraging colleagues & & & & & & & & \\
\hline to read & $4.0(4.0,5.0)$ & $4.34 \pm 0.77$ & $4.0(4.0,5.0)$ & $4.31 \pm 0.77$ & $4.0(4.0,5.0)$ & $4.24 \pm 0.75$ & $4.0(3.0,5.0)$ & $3.92 \pm 0.94$ \\
\hline Applying research findings & $5.0(4.0,5.0)$ & $4.43 \pm 0.73$ & $5.0(4.0,5.0)$ & $4.37 \pm 0.76$ & $4.0(4.0,5.0)$ & $4.33 \pm 0.77$ & $4.0(3.0,5.0)$ & $3.93 \pm 0.97$ \\
\hline Initiating research & $4.0(4.0,5.0)$ & $4.13 \pm 0.84$ & $4.0(4.0,5.0)$ & $4.13 \pm 0.85$ & $4.0(4.0,5.0)$ & $4.16 \pm 0.91$ & $4.0(3.0,4.0)$ & $3.64 \pm 1.0$ \\
\hline
\end{tabular}

$\mathrm{q}_{1}=$ Upper quartile; $\mathrm{q}_{3}=$ lower quartile.

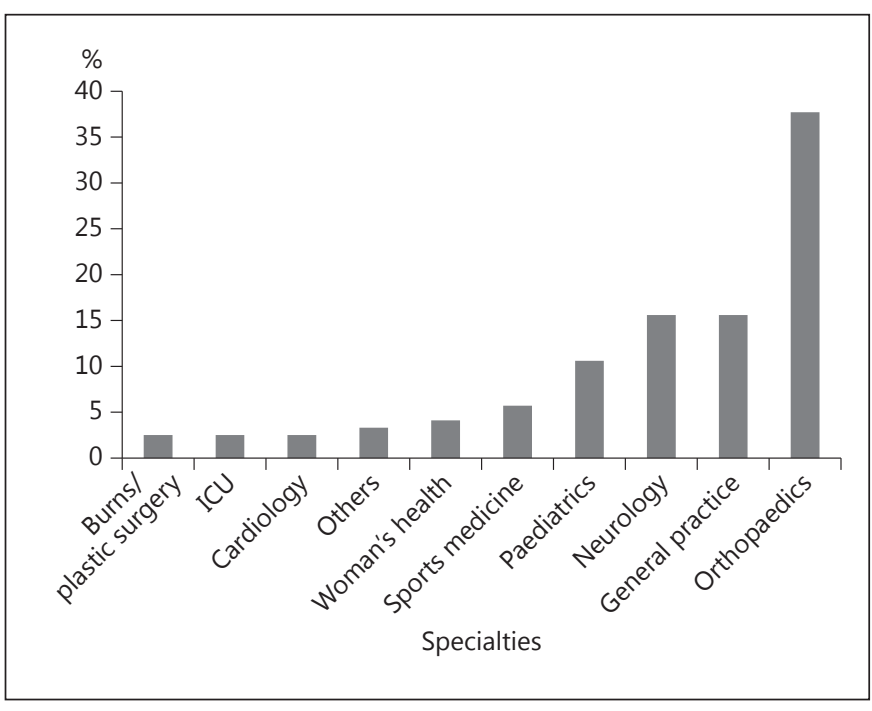

Fig. 1. Area of specialty of the study participants.

8.5 years (range: $21-63$ years). Sixty-eight $(55.7 \%)$ of the participants were clinicians, $73(59.8 \%)$ of the participants had less than 10 years of clinical experience equating to a mean of $10.1 \pm 8.4$ years. Ninety-six $(78.7 \%)$ of the participants held entry-level (undergraduate) degrees. While $16(13.1 \%)$ of the participants had undertaken clinical research, $52(42.6 \%)$ had published their work, mainly as an abstract or poster. Sixty-seven (54.9\%) of the participants involved in this study were employed in a general hospital, with the highest number of the participants, $46(37.7 \%)$, practicing orthopaedics, and the least were in burns and plastic surgery (3;2.5\%) (fig. 1).

In general, the participants' responses ranged from 'agree' to 'strongly agree' that they have the responsibility, ability and intention to further update their knowledge

Research amongst Physical Therapists in Kuwait through further reading and study. Similarly, participants strongly agreed that they have a role and the ability to apply research findings to improve physical therapy practice. However, there existed a common belief that they possessed less of a role, and less ability and intention, and that they were less engaged in initiating research and encouraging colleagues to further their reading (table 1).

Furthermore, the attitude of the study participants towards research-related activities was positive. Hence, the means for the four research-related activities were relatively similar (reading research: $1.34 \pm 1.3$; encouraging colleagues to read: $1.04 \pm 1.3$; applying research findings: $1.42 \pm 1.2$; initiating research: $1.29 \pm 1.2$ ). The most relevant attitude identified was towards the application of research findings to improve physical therapy practice. Another important positive attitude recognized was reading research materials to update the participants' knowledge (table 2).

\section{Association of Research-Related Dimensions with Demographics}

The level of education had a significant association with the intent to engage in research-related activities $(p=0.05)$. Results showed that more baccalaureate degree holders intended to, and currently engage in, researchrelated activities. Furthermore, the nature of the participants' work was significantly associated with engagement in research-related dimensions $(\mathrm{p}=0.01)$. Currently, clinicians perform the most research-related activities. Other demographics were not significantly associated with any of the research-related dimensions examined.

\section{Working Conditions and Association with}

Engagement in Research-Related Activities

Of the 122 participants, 55 (45.1\%) had set time aside to read research articles; however, 48 (39.3\%) did not set 
Table 2. Medians, upper and lower quartiles for attitudes to research-related activities, and means \pm SD for attitude index scores

\begin{tabular}{llllll}
\hline & $\begin{array}{l}\text { Interesting-boring } \\
\text { median }\left(\mathrm{q}_{1}, \mathrm{q}_{3}\right)\end{array}$ & $\begin{array}{l}\text { Attractive-repulsive } \\
\text { median }\left(\mathrm{q}_{1}, \mathrm{q}_{3}\right)\end{array}$ & $\begin{array}{l}\text { Easy-difficult } \\
\text { median }\left(\mathrm{q}_{1}, \mathrm{q}_{3}\right)\end{array}$ & $\begin{array}{l}\text { Necessary-unnecessary } \\
\text { median }\left(\mathrm{q}_{1}, \mathrm{q}_{3}\right)\end{array}$ & $\begin{array}{l}\text { Index } \\
\text { mean } \pm \mathrm{SD}\end{array}$ \\
\hline Reading research & $2.0(0.0,3.0)$ & $1.0(0.0,3.0)$ & $1.0(0.0,2.0)$ & $3.0(1.0,3.0)$ \\
Encouraging colleagues to read & $1.0(0.0,3.0)$ & $1.0(0.0,2.0)$ & $0.0(-1.0,2.0)$ & $3.0(0.0,3.0)$ & $1.34 \pm 1.3$ \\
Applying research findings & $2.0(1.0,3.0)$ & $2.0(0.0,3.0)$ & $0.0(0.0,2.0)$ & $2.0(0.0,3.0)$ & $1.04 \pm 1.3$ \\
Initiating research & $2.0(1.0,3.0)$ & $2.0(0.0,3.0)$ & $0.0(-1.0,2.0)$ & $2.0(1.0,3.0)$ \\
\hline
\end{tabular}

$\mathrm{q}_{1}=$ Upper quartile; $\mathrm{q}_{3}=$ lower quartile. ${ }^{1}$ Attitude index: the four research activities were added together.

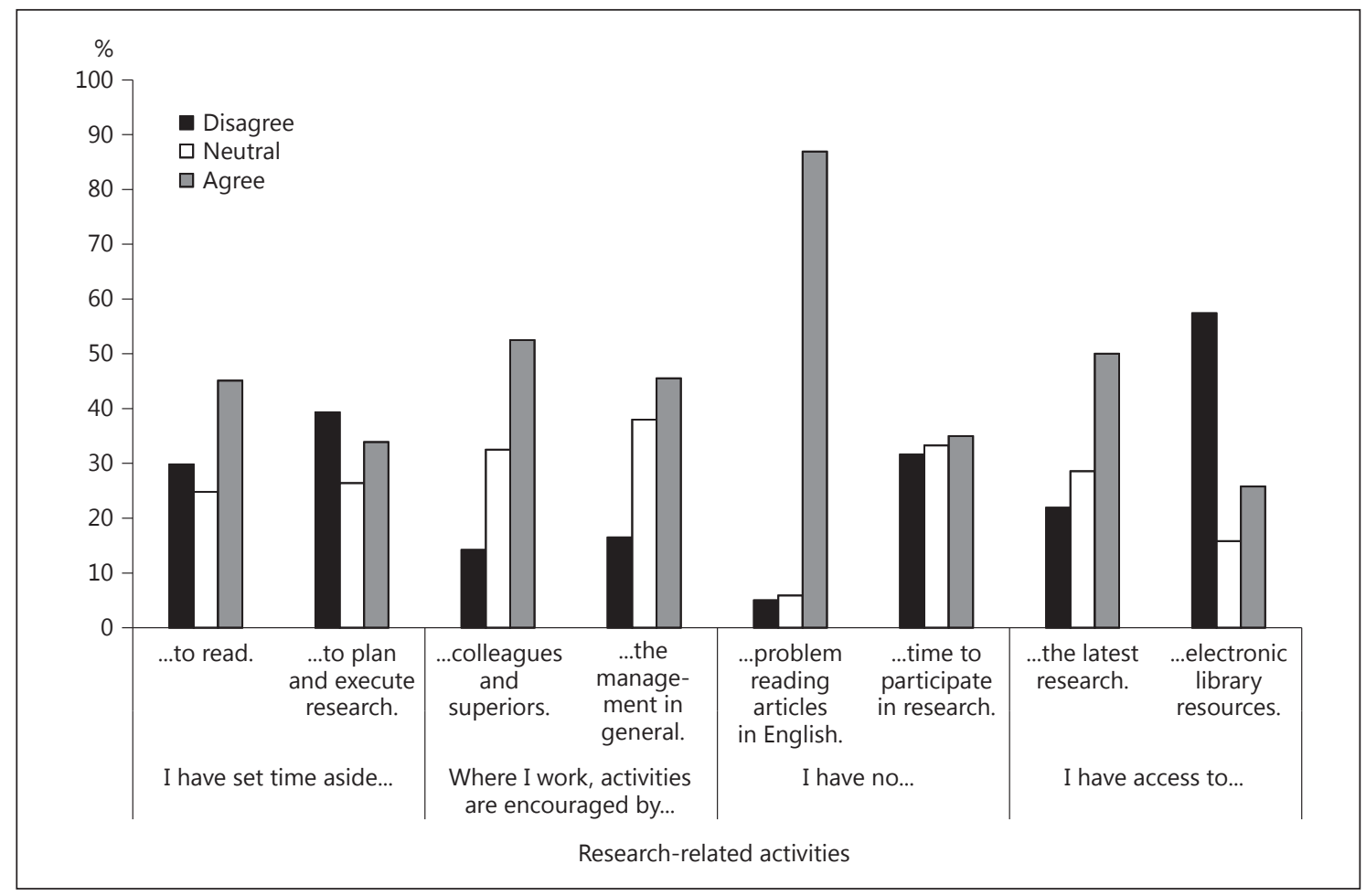

Fig. 2. Work conditions and association with engagement in research-related activities.

time aside to plan and execute research during working hours. Sixty-four (52.5\%) of the participants had agreed that at their workplace research activities were encouraged by colleagues, superiors and the management. One hundred and six (86.9\%) had not reported any problem with reading articles in English. In addition, 61 (50\%) did not report any problem in obtaining the latest research results relevant to their area of practice. Forty-one (33.6\%) had stated that they did not have time to take part in any research-related activities due to their high work load.
Seventy (57.4\%) further added that they did not have access to electronic library resources and material at their workplace (fig. 2).

\section{Reading Relevant Scientific Articles}

The study participants listed 19 scientific journals that contained relevant physical therapy research publications. The journals of the American Physical Therapy Association (APTA) were ranked first as the journals containing the most relevant research topics and studies, fol- 
lowed by the Journal of the Chartered Society of Physiotherapy and the Journal of the Indian Association of Physiotherapists. Similarly, the journal of the APTA was the most-read journal (19.4\%), followed by the Journal of the Chartered Society of Physiotherapy (14.5\%) and the Journal of the Indian Association of Physiotherapists $(12.1 \%)$.

\section{Discussion}

Overall, physical therapists in this study had positive attitudes towards the application of research findings to their practice and towards reading physical therapy research to update their knowledge. However, there was a common belief that they had less of a role, as well as a reduced ability, intention and level of engagement, in initiating research. This could probably be due to work overload, lack of time and limited access to library resources; this was made evident by the low level of contribution to research.

The positive attitude particularly towards the application of study findings related to physical therapy practice, and towards reading physical therapy journals, is a probable indicator of a shift towards evidence-based practice. Therefore, it was common practice for the participants to study the literature, learn new therapeutic techniques that are evidence based and then apply these techniques therapeutically on their patients. These findings, however, indicate that the majority of the participants used research findings rather than actively conducting their own research. Furthermore, the results show that very few of the physical therapists involved had contributed to research. The findings also indicate that the physical therapists involved in this study did not perceive themselves to be competent in initiating research. This could be attributed to a lack of skill in initiating and conducting their own research. Therefore, the methods for improving research skills need to be addressed and greater efforts should be made to enhance engagement in research.

The positive attitudes towards research reported in this study confirm the findings of previous studies [3, 8]. Similarly, the low level of contribution to research also confirms findings of previous studies $[6,17]$. However, the level of research involvement reported in this study (17\%) was still higher than previously reported percentages (0.6$12.2 \%)$ amongst physical therapists in the USA $[6,17]$. Ballin et al. [6] reported that only $0.6 \%$ of Californian physical therapists spent $50 \%$ or more of their on-the-job time on research activities, with $84 \%$ stating that none of their on-the-job time was spent on research, while Gross et al. [17] reported that $12.2 \%$ of the physical therapists in their study were involved in research activities.

In agreement with previous studies [3,8], it is advisable that a high level of involvement in research and commitment to the profession are anticipated amongst physical therapists. In this study, clinicians with baccalaureate degrees possessed a great sense of responsibility concerning their profession; that is manifested by a greater level of interest and willingness to participate in research, which is derived from their abundant clinical experience.

The key barriers to research identified in this study overwork, lack of planning time, the inability to conduct research during working hours, and lack of access to electronic library resources and material at the workplace are similar to those reported previously $[3,6,18]$.

Because of the relevance of research, its application in health care delivery and the emphasis on evidence-based practice, the findings of this study could contribute to the development of a curriculum in physical therapy that should emphasize research and evidence-based practice in physical therapy.

The study has several limitations; first, the study sample was convenient, thus it could affect the generalizability of the study findings. The sample, however, represented one third of all physical therapists working in Kuwait. The second limitation is the low response rate (61\%). The third limitation is that this study did not investigate the research barriers in depth, nor the factors which facilitate engagement in research. These limitations, however, will be the focus of ongoing future research.

\section{Conclusions}

The findings of this study indicate that physical therapists in Kuwait had a great sense of responsibility and a positive attitude towards research. However, limiting factors regarding research as reported by the participants included work load, lack of time and limited access to library resources. Hence, we recommend the development of a system to stimulate engagement in research-related activities among physical therapists in Kuwait.

\section{Acknowledgement}

The authors would like to thank the physical therapists who actively participated in the data collection process. 


\section{References}

1 Tammivaara J, Shepard KF: Theory: the guide to clinical practice and research. Phys Ther 1990;70:578-582.

2 American Physical Therapy Association: Vision 2020: vision sentence for physical therapy and vision statement for physical therapy. 2012. http://www.apta.org/vision 2020 .

-3 Kamwendo K: What do Swedish physiotherapists feel about research? A survey of perceptions, attitudes, intentions and engagement. Physiother Res Int 2002;7:23-34.

4 Kamwendo K, Törnquist K: Do occupational therapy and physiotherapy students care about research? A survey of perceptions and attitudes to research. Scand J Caring Sci 2001; 15:295-302.

5 Connolly B, Lupinnaci NS, Bush AJ: Changes in attitudes and perceptions about research in physical therapy among professional physical therapist students and new graduates. Phys Ther 2001;81:1127-1134.

6 Ballin AJ, Breslin WM, Wierenga KA, et al: Research physical therapy: philosophy, barriers to involvement, and use among California physical therapists. Phys Ther 1980;60:888895.
7 Morrissey MC, Kanda LT, Brewster CE: Development of a clinical physical therapy research program. Phys Ther 1987;67:11101114

8 Warren SC, Pierson FM: Comparison of characteristics and attitudes of entry-level bachelor's and master's degree students in physical therapy. Phys Ther 1994;74:333-348.

9 Closs SJ, Lewin BJP: Perceived barriers to re search utilization: a survey of four therapies. Br J Ther Rehabil 1998;5:151-155.

10 Tobin A, Judd M: Experiencing the barriers. Physiotherapy 1999;85:6-10.

11 Ehrenfeld M, Eckerling S: Perceptions and attitudes of registered nurses to research: a comparison with a previous study. J Adv Nurs 1991;16:224-232.

12 Eckerling S, Bergman R, Bar-Tal Y: Perceptions and attitudes of academic nursing students to research. J Adv Nurs 1988;13:759767.
Caldwell PH, Craig JC, Butow PN: Barriers to Australian physicians' and paediatricians' involvement in randomised controlled trials. Med J Aust 2005;182:59-65.

14 Sumi E, Murayama T, Yokode M: A survey of attitudes toward clinical research among physicians at Kyoto University Hospital. BMC Med Educ 2009;9:75

15 Jacobson AF: Research utilization in nursing: the power of one. Orthop Nurs 2000;19:6165.

16 Jacobson AF, Warner AM, Fleming E, et al: Factors influencing nurses' participation in clinical research. Gastroenterol Nurs 2008;31: 198-208.

17 Gross MT, Sekerak DK, Allen DD: Effect of including a clinical example on the ability of physical therapists to apply information in a technical research report. Phys Ther 1994;74: 963-968.

18 Humphris D: Managing knowledge into practice. Man Ther 1998;3:153-158. 